\title{
La agricultura familiar como campo de intervención e investigación social
}

Marcos Andrés Urcola

Licenciado en Trabajo Social (Universidad Nacional de Rosario)

Doctor en Humanidades y Artes con mención en Antropología (Universidad Nacional de Rosario)

Becario CONICET (Universidad Nacional de Rosario)

Correo:murcola@hotmail.com 
Resumen

El artículo presenta, a modo de ensayo, lo ejes centrales que hacen a la agricultura familiar como categoría empírico-conceptual que expresa las contradicciones y conflictos del mundo agrario y rural actual. En función de esto, se ofrece una descripción de la importancia que ha cobrado la temática en nuestro país y sus potencialidades como espacio para el desempeño profesional y académico del Trabajo Social.

Palabras clave agricultura familiar, ruralidad, Trabajo Social

\begin{abstract}
This article presents, as an essay, the central aspects that make family farming as a empiricalconceptual category that expresses the contradictions and conflicts of nowadays agricultural and rural world. On this basis, it provides a description about the importance that has gained the subject in our country and its potential as a space for the professional and academic performance of Social Work.
\end{abstract}

Keywords

family farm, rural issue, Social Work 


\section{Introducción ${ }^{19}$}

La intención de este ensayo es desarrollar los ejes centrales de un tema marginal o poco trabajado en el ámbito académico-universitario del Trabajo Social argentino, principalmente en las unidades académicas de radicación pampeana (como las de la Universidad Nacional de Rosario o la del Litoral).

Si bien la temática de la agricultura familiar suele inscribirse dentro del terreno de la sociología y la antropología rural, durante los últimos tiempos se ha constituido en un tema-categoría de articulación entre los debates teóricos y los procesos concretos de intervención para la implementación de políticas públicas que resultan de gran interés para pensar la pertinencia disciplinar del Trabajado Social.

En términos sociológicos y antropológicos podemos rastrear el interés por la agricultura familiar en los estudios campesinos de los ‘ 60 y'70 y sobre la funcionalidad de la pequeña producción de los ‘ 80 y mediados de los '90 (Schneider, 2014). No obstante, es a comienzos del nuevo milenio cuando esta categoría toma relevancia en nuestro continente en el marco de las propuestas de intervención para el desarrollo de los territorios rurales (Sabourin et al, 2014). Entre el 2000 y el 2015, podemos señalar cierto auge y moda de esta categoría para englobar el estudio y la intervención sobre determinados problemas del mundo agrario y rural desde diferentes perspectivas.

En términos generales, la agricultura familiar se ha presentado como una categoría que ha permitido describir, clasificar e identificar determinados sujetos y dinámicas socio-económicas propias del mundo rural (la del campesino o el pequeño productor agropecuario y su mundo de relaciones), pero por sobre todas las cosas, se ha presentado como un gran paraguas conceptual y empírico para la

19 Las reflexiones plasmadas en este ensayo fueron presentadas en el panel sobre Agricultura Familiar realizado en el marco de las II Jornadas de Estudiantes de Trabajo Social del Litoral: "Experiencias de escritura académica", durante los días 1, 2 y 3 de noviembre de 2018 en la Facultad de Ciencias Jurídicas y Sociales de la Universidad Nacional del Litoral (UNL), en la ciudad de Santa Fe (Argentina). Se agradece a las organizadoras del encuentro por la invitación y la posibilidad de compartir en este panel parte de las líneas de investigación que he llevado adelante durante los últimos 10 años. Y a las colegas y estudiantes participantes por sus preguntas y comentarios que permitieron mejorar la versión escrita que se presenta a continuación. Del mismo modo, se agradecen las observaciones y sugerencias de los/las revisores del artículo que permitieron dar un mejor orden expositivo y conceptual al mismo. 
discusión académica y la promoción de políticas que aborden las contradicciones y conflictos de los territorios rurales actuales.

En los siguientes apartados se presentarán los aspectos centrales de este campo analítico e interventivo ${ }^{20}$, con anclaje en las particularidades del caso argentino. Para ello, se desagrega expositivamente a la agricultura familiar en dos dimensiones: una teórico-conceptual y otra político-instrumental. Finalmente, se ofrecen algunas reflexiones en torno a su pertinencia y potencialidad actual para el desempaño profesional en el marco de los conflictos por las formas de apropiación y usos del territorio y sus bienes naturales.

\section{Dimensión teórico-conceptual: ¿qué es un agricultor familiar? ¿A qué problemas teóricos y empíricos remite?}

Inevitablemente, los antecedentes académicos sobre las formas de producción agrícola de base familiar remiten a los desarrollos teóricos que dieron origen a las ciencias sociales modernas mismas (sociología y antropología fundamentalmente), donde el estudio del campesinado y de las formas de producción precapitalistas tenían un peso importante en sus análisis (tanto en las producciones marxistas como las comprensivas o de matriz positivista).

No obstante, a pesar de la relevancia de estos antecedentes, la noción de agricultura familiar debe ser inscripta en el debate académico y político sobre los procesos de modernización y desarrollo de la segunda posguerra. Luego de la Segunda Guerra Mundial el desarrollo es entendido como una política internacional y nacional de modernización de los países y de las comunidades rurales bajo una concepción evolucionista (unilineal y universal) que plantea como

20 Hacemos uso de la noción bourdiana de campo para referirnos en términos generales a las luchas empíricas y simbólicas que se dan en torno a la definición e identificación de problemas y sujetos sociales concretos. Una mayor profundización de los alcances teórico-metodológicos de este concepto excede los objetivos y posibilidades espaciales de este artículo (véase Bourdieu, 1990). No obstante, en este caso particular, con su uso queremos destacar la vinculación empírico-conceptual entre agricultura familiar como categoría analítica y la agricultura familiar como categoría instrumental para el diseño de políticas públicas, donde diferentes actores pujan por establecer como legítimo aquello que los define socialmente. 
modelo de llegada a los países capitalistas dominantes de occidente y que asocia desarrollo con crecimiento económico (Lattuada, 2014).

La agricultura familiar emerge como resultado de construcciones tipológicas en el marco de acciones para el desarrollo vinculadas al modelo agrícola francés de la segunda posguerra ${ }^{21} \mathrm{y}$ las propuestas de reforma agraria del Comité Interamericano de Desarrollo Agrícola (CIDA) en Latinoamérica (en el marco de la Alianza para el Progreso) (Giarracca, 1999).

Desde la perspectiva de la modernización (cuyo anclaje sociológico será el estructural funcionalismo) se sostenía la necesidad de lograr la transición de las sociedades tradicionales (agrarias o rurales) hacia las sociedades modernas (industriales o urbanas) a través del pasaje de la hacienda a la empresa agropecuaria y de la comunidad campesina a la pequeña producción familiar (Bengoa, 2003). De este modo, se desplazaba la comunidad como unidad de análisis por el productor y su unidad productiva (es decir, la Explotación Agropecuaria -EAP-). ${ }^{22}$

Lo importante que queremos señalar acá es que la agricultura familiar o el agricultor familiar, tendió a emerger como el sujeto de las acciones y debates en torno al desarrollo y las políticas y programas de desarrollo rural en el que convergen las discusiones previas del mundo académico sociológico y antropológico sobre el campesinado y el mundo rural en general.

En estos debates, la referencia a la agricultura familiar se ha vinculado, por un lado, con intereses taxonómicos (para definir aspectos de la estructura agraria) y, por otro, con intereses políticos vinculados

\footnotetext{
21 En el modelo agrícola francés, la "industrialización" de la agricultura se hizo sobre la base de una fuerza de trabajo y un capital esencialmente familiar, impulsada por el Estado y organizada en torno a explotaciones medias, fomentando la profesionalización de la agricultura y el encuadre técnico y sindical del campesinado (véase Schiavoni, 2010).

22 Desde entonces, la clasificación de unidades o establecimientos agropecuarios ha sido uno de los recursos metodológicos en torno a los que han girado las discusiones académicas para la medición estadística y morfológica de la estructura social rural en diferentes épocas. La construcción de tipologías de explotaciones agropecuarias (EAP) permitió identificar y clasificar los diversos agentes productivos, en función de la forma en que se combina: trabajo humano y tecnología, superficie operada, forma de tenencia y uso de la tierra, organización social del proceso productivo, nivel de capitalización y racionalidad económica (véase Urcola, 2011).
} 
a sus posibilidades de generar procesos de desarrollo en los territorios rurales. ${ }^{23}$

Es difícil encontrar una noción unívoca de agricultura familiar ya que, tanto investigadores como quienes elaboran políticas de desarrollo rural, no concuerdan en una definición y la misma difiere en forma considerable según la región o el país de referencia y la posición teórica dentro de la que se la inscribe.

La forma de organización del trabajo y el tipo de mano de obra utilizada, han sido las variables mayormente utilizadas como indicadores de la presencia de unidades productivas de tipo familiar. La existencia de trabajo familiar o no familiar (asalariado) y el tipo de labores y división del trabajo que se dan los miembros de la organización productiva (tareas administrativas y de dirección, participación directa en las labores productivas) han determinado la inclusión o no de cada establecimiento dentro del rubro de explotación agropecuaria (EAP) de tipo familiar.

En Argentina, utilizando datos del Censo Nacional Agropecuario del 2002, el estudio realizado por Obschatko et al (2007) definió a las explotaciones agropecuarias de pequeños productores (PP) como aquellas en las que el productor o socio trabaja directamente en la explotación y no emplea trabajadores no familiares remunerados permanentes. Con esta definición, se entendía que la expresión "pequeño productor" era equivalente a la de "productor familiar", permitiendo identificar y visibilizar a los agricultores familiares dentro de sector agropecuario nacional ${ }^{24}$.

23 Uno de los debates que, en forma explícita e implícita, forman parte del repertorio teórico y empírico de discusión en torno a la agricultura familiar, es el que se dio entre campesinistas (o populistas) y descampsinistas (o proletaristas) durante la década de 1970. Los campesinistas planteaban la posibilidad de una vía de desarrollo campesina a través de la integración vertical de cooperativas que preservaran la unidad doméstica campesina para integrarla a los mercados. En función de estas propuestas se sostiene que, con el apoyo del Estado y la investigación agrícola, las unidades productivas de base familiar podrían abastecer al mercado interno. Leopoldo Bartolomé es quien introduce estos debates en Argentina (véase Bartolomé, 1972).

24 Para medir la diversidad de casos que engloba esta definición, se establecieron 3 estratos de PP utilizando como criterio el nivel de capitalización: un estrato superior de unidades familiares capitalizadas (Tipo 1) que pueden desarrollarse económicamente y sus carencias se vinculan con la falta de acceso a servicios de apoyo a la producción (asistencia técnica, comercial y financiera); un estrato intermedio (Tipo 2) de productores familiares (campesinos o de reproducción simple) cuya escasez de recursos sólo les permite mantenerse en la actividad sin posibilidades de crecimiento y con algunos rasgos de pobreza como la falta de acceso a servicios sociales básicos; y un estrato inferior de 
En un segundo estudio, Obschatko (2009) amplió el universo de los PP, agregando aquellas EAP en las que, además de contar con el trabajo directo del productor y su familia, contratan hasta dos personas no familiares remuneradas en forma permanente. Con esta nueva definición, se agrega un estrato de EAP que, manteniendo las características de la EAP Familiar, introduce la relación salarial permanente. Su inclusión generó un amplio debate y objeciones, ya que este aspecto tensiona al máximo las características de los actores incluidos bajo la categoría de agricultor o productor familiar, pero a su vez permitía una visión más laxa e inclusiva para la aplicación de políticas y programas con la diversidad de sujetos que presentaba la territorialidad rural y agraria Argentina.

A pesar de las objeciones mencionadas, los estudios del PROINDER-IICA ${ }^{25}$ se han constituido hasta el día de hoy en los dos estudios oficiales de referencia para medir el peso económico y social de la agricultura familiar en el país. En este sentido, los mismos tuvieron una finalidad más práctica y vinculada a la necesidad generar un soporte empírico para el diseño y la formulación de políticas públicas que con fines de contribuir a las discusiones académicas de larga data. El último de estos estudios (Obschatko, 2009) identificó 251.116 establecimientos de agricultura familiar $(75.3 \%$ del total de establecimientos del país), ocupando 30,9 millones de hectáreas (17,7\% de la superficie bajo producción). Dichos agricultores representan entre el $85 \%$ y el $94 \%$ de los establecimientos que producen tabaco, algodón, yerba mate, caña de azúcar, papa, cebolla, acelga y tomate y más del $50 \%$ entre los que producen granos (maíz, soja, trigo y girasol). También generan el $64 \%$ del empleo total agropecuario y el $27 \%$ del valor de producción del sector.

productores familiares pobres o de subsistencia (T3) cuya dotación de recursos no les permite vivir exclusivamente de la explotación y mantenerse en la actividad, presentando múltiples necesidades básicas insatisfechas (NBI) (Obschatko et al, 2007:37).

25 Ambos estudios fueron encargados y financiados por el Proyecto de Desarrollo de Pequeños Productores Agropecuarios (PROINDER) de la ex Secretaría de Agricultura, Ganadería, Pesca y Alimentación (SAGPyA) y el Instituto Interamericano de Cooperación para la Agricultura (IICAArgentina). 
De este modo, la construcción de tipologías de unidades productivas ha conformado parte importante de la consolidación del modelo de agricultura familiar como categoría clasificatoria y descriptiva a la vez que, muchas veces, ha hecho ceder ante la tentación de explorar sus combinaciones abstractas en desmedro de la materialidad del fenómeno social estudiado con un adecuado equilibrio entre la esquematización propuesta y la realidad empírica de referencia (Urcola, 2011). Cabe señalar que en la distancia que se observa entre el productor de subsistencia o de tipo campesino y el productor más capitalizado o de empresa familiar agraria en las tipologías de agricultura familiar plateada por el estudio del PROINDER-IICA (Obstchatko, 2009), la acción pública corre el riesgo de quedar desdibujada por la diversidad de casos comprendidos y corre el riesgos de desvirtuar la dimensión cultural que sostiene a este grupo como una forma particular de vida rural y de hacer agricultura.

En un intento de síntesis y de superar esta dispersión analítica y empírica generada por la gran variedad de estudios que plantearon variables esencialmente económico-productivos, Balsa (2012) ha intentado la construcción de una definición típico-ideal (en términos weberianos) que integre estos aspectos con los socio-culturales en una definición conceptual ${ }^{26}$.

De este modo, sostiene que hay tres rasgos que permiten identificar a las unidades productivas familiares arquetípicas. Estas son aquellas en las que:

1) no se explota trabajo asalariado;

2) la familia conforma un equipo de trabajo; y

3) presentan una racionalidad particular, propia de la conjunción de (a) la integración entre unidad productiva y doméstica, (b) el papel que juega en la dinámica productiva-familiar la conservación del patrimonio familiar, y (c) la existencia de un proyecto de vida vincu-

26 En ciencias sociales, la elaboración de conceptos ha operado históricamente como un recurso metodológica y analítico que ha permitido recuperar los rasgos que tipifican a un fenómeno estudiado, intentando comprender cuál es la racionalidad propia que determina las condiciones de existencia del mismo en un momento histórico determinado, para, a su vez, poder contrastar con la realidad empírica e indicar la dinámica que hace a la actualidad de las relaciones sociales entre los actores involucrados en contextos sociales particulares (véase Urcola, 2011). 
lado a la actividad agropecuaria y con un cierto modo de vida rural deseable (Balsa, 2012).

Con fines explicativos y analíticos, esta definición resulta de gran utilidad para dar cuenta de las particularidades y complejidades que implica el reconocimiento de esta forma social y productiva específica en el territorio nacional argentino, ya que la misma debe intentar comprender realidades tan diversas como la de los "chacareros" pampeanos o la de los pobladores rurales con rasgos campesinos del Norte de nuestro país.

A partir de esta definición conceptual podemos advertir que, en esencia, la Agricultura Familiar se ha presentado como una categoría que ha intentado aglutinar a los actores cuyas lógicas de acción económica, social y política se diferencia de la de los agentes empresariales $\mathrm{o}$ agroindustriales.

En síntesis, la agricultura familiar se ha conformado en una categoría descriptiva y analítica que ha intentado aglutinar con fines analíticos académicos y para el diseño de políticas de desarrollo rural a un vasto universo de actores agro-rurales. Con este fin, ha transitado una serie de tensiones vinculadas a sus excesivos usos técnicoinstrumentales (en detrimento de otras categorías analíticas como la de campesino) y a la tentación de ofrecer visiones extremadamente simplificadas del mundo rural (minifundio-latifundio, unidades familiares-unidades empresariales) o, por el contrario, demasiado amplias en función de abarcar la gran diversidad de casos empíricos que la comprenden.

Como bien nos indican Lattuada et al (2012), lo central en esta categoría no parece ser la familia ni la agricultura, sino la evidencia de que los sujetos a cargo de las actividades económicas rurales no son todos iguales y que aquello que los conforma de manera diferente es tanto su modo de hacer como su relación con el medio rural. Es por esto que se trata sobre todo de una categoría política, donde subyace la idea de la existencia de grandes asimetrías en materia de información, acceso a recursos y poder entre los sujetos de la agricultura familiar y los de la agricultura empresarial o industrial. 
La agricultura familiar no refiere a un sujeto aislado sino en relación con otros. Estas relaciones pueden ser de confrontación y conflicto o de articulación subordinada en cadenas productivas, pero en ambos casos las políticas públicas y el Estado cumplen un rol central que debe ser comprendido dentro del mismo espacio de relaciones empíricas y conceptuales al que nos referiremos en el apartado siguiente.

\section{Dimensión político-instrumental: políticas públicas y desarrollo rural}

Según Schiavoni (2010), en América Latina la agricultura familiar fue una categoría acuñada inicialmente por sindicatos y organizaciones de desarrollo rural en Brasil para la organización territorial de los procesos económicos, en el contexto de descentralización y retracción del Estado de la década de 1990. Son el Ministerio de Desarrollo Agrario y el de Relaciones Exteriores de Brasil quienes, en junio de 2004, llevan al Grupo del MERCOSUR la propuesta de creación de la Reunión Especializada de Agricultura Familiar (REAF). La creación de la misma tuvo el objeto de incluir en la agenda regional a la agricultura familiar como sujeto de las políticas públicas para reducir las asimetrías e integrar económica, política y socialmente a los países de la región (véase Nogueira \& Urcola, 2013).

A su vez, hacia finales de la década de 1990, se difunde en nuestra región un "nuevo discurso" vinculado a temas y acciones del desarrollo endógeno, gestión estratégica de ámbitos locales, participación y territorio (Nogueira \& Urcola, 2013). Se introduce el paradigma del Desarrollo Territorial Rural (DTR) que comienza a permear la lógica de acción de los programas de desarrollo hasta la actualidad. En esta perspectiva, se recomienda una estrategia de desarrollo rural que contribuya a la cohesión y la inclusión social estimulando y facilitando la vinculación competitiva de los territorios rurales a mercados más dinámicos, la coordinación y las relaciones de cooperación entre los agentes económicos, sociales y gubernamentales y la inclusión de los sectores pobres y socialmente excluidos, así como también de la micro y la pequeña empresas agro-rurales en los procesos de transfor- 
mación productiva y desarrollo institucional (Schejtman \& Berdegué, 2004). En el DTR, uno de los actores protagónicos del desarrollo rural será -por presencia o ausencia- el Estado y, por otro lado, una diversidad de actores locales que comienzan a aglutinarse bajo la categoría de agricultura familiar.

En el marco de este cambio de paradigma, el concepto de agricultura familiar aparece como una noción más abarcadora respecto de la de pequeño productor o minifundista que hacían hincapié en las condiciones de pobreza o escasez (predial o de capital). Dado que el verdadero reto de esta propuesta era poner en marcha procesos de transformación que incluyeran a los pobres, a los excluidos y a los micro y pequeños empresarios rurales, la categoría de agricultura familiar se presentó como una noción que permitió representar a este abanico de actores. Evidentemente el rasgo "familiar" es el que otorgó consenso político a la categoría y el que posibilitó trascender las condiciones económicas de pobreza como indicador exclusivo para su identificación.

En Argentina, a pesar de su importancia académica, la agricultura familiar no había sido históricamente un sujeto o tema relevante de la agenda política del sector agropecuario, sino más bien un agente residual de la misma. Tal como sostienen Manzanal y Schneider (2011), a la inversa de lo que sucedió en el caso brasileño, las políticas de desarrollo rural y agricultura familiar en Argentina no surgen como consecuencia de la demanda de las organizaciones de productores, sino desde el Estado y en particular de los organismos de financiamiento internacional como el Fondo Internacional de Desarrollo Agrícola (FIDA) y organismos regionales como la REAF-MERCOSUR.

La REAF comenzó a pautar una agenda de trabajo conjunto entre organizaciones representativas de la agricultura familiar y la entonces Secretaría de Agricultura, Ganadería, Pesca y Alimentación (SAGPyA) en Argentina. Estos encuentros, sentaron las bases del Foro Nacional de la Agricultura Familiar (FoNAF), inaugurado en diciembre de 2005 y formalizado en marzo de 2006, en cuyo seno se 
integraron alrededor de 900 organizaciones de agricultores familiares y pobladores rurales del país ${ }^{27}$.

Tal como sostiene Soverna et al (2008), lo novedoso de estos espacios no tuvo que ver con el uso del concepto, sino con que el mismo apareciera asociado a la necesidad de definir políticas diferenciales hacia el sector.

En este contexto, debe destacarse la creación en 2008 de la Subsecretaría de Desarrollo Rural y Agricultura Familiar de la Nación, con el objetivo de identificar, diseñar y ejecutar políticas y programas que atiendan a las necesidades específicas de este sector. Si bien los procesos de diálogo político impulsados por la REAFMERCOSUR son los que logran instalar la problemática en el país, es el llamado "conflicto campo-gobierno" del año 2008 el que puso en agenda pública la temática agropecuaria y generó un mayor interés del gobierno argentino por la agricultura familiar para dar respuesta a los planteos opositores ${ }^{28}$. La importancia de la agricultura familiar como categoría socio-económica y política ha ido creciendo desde entonces con una clara jerarquización de la "cuestión" a partir de esta Subsecretaría y su posterior elevación al rango de Secretaría con la creación del Ministerio de Agricultura, Ganadería y Pesca en 2009 (y una específica Subsecretaría de Agricultura Familiar en su interior). A su vez, entre 2004 y 2014, se formularon programas específicos de investigación y desarrollo al interior del INTA (como el Centro de Investigación y Desarrollo Tecnológico para la Pequeña Agricultura Familiar -CIPAF- en 2005), se rediseñaron los pro-

27 El mismo contó con la participación de muchas de las organizaciones creadas en el marco de programas de desarrollo rural en la década de 1990 y de organizaciones de carácter histórico que merece especial mención, tales como: el Movimiento Agrario Misionero (MAM) o el Movimiento Campesino de Santiago del Estero (MOCASE), el Movimiento Campesino de Misiones (MOCAMI) y la Federación Agraria Argentina (FAA). Esta última tradicional organización corporativa del agro argentino participó de un modo relevante en el Foro hasta el año 2008 a través de su Departamento de Desarrollo Rural. Ese año se retiró del espacio, luego del conflicto entre el Gobierno Nacional y las organizaciones tradicionales del agro pampeano.

28 El mismo está asociado a la propuesta de aumento de las retenciones sobre las exportaciones granos y carne vacuna y tuvo como principales protagonistas a las cuatro organizaciones corporativas tradicionales del sector agropecuario del país -Sociedad Rural (SRA), Federación Agraria Argentina (FAA), Confederaciones Rurales Argentinas (CRA) y Confederación Intercooperativa Agropecuaria (CONINAGRO)-, contando, además, con el apoyo de sectores urbanos medios y altos (véase Hora, 2010). 
gramas heredados de la década de 1990dando mayor centralidad a este sujeto (PSA, PROINDER, PRODERNEA, PRODERNOA, Minifundio, PROHUERTA, Cambio Rural, entre otros) y se sancionó la ley 27.118 de "Reparación Histórica de la Agricultura Familiar para la construcción de una Nueva Ruralidad en la Argentina" (véase Nogueira et al, 2017).

En este sentido, el auge actual del término agricultura familiar se relaciona más con sus usos político-instrumentales que teóricoconceptuales o taxonómicos. Para el logro de sus objetivos, cada política o programa hace su recorte de la realidad, seleccionando y tipificando los sujetos destinatarios de sus acciones, bajo diversos supuestos teórico-metodológicos que guían su ejecución. Como bien indica Craviotti (2014), los significados de un concepto están ligados a los usos que se les otorgue en diferentes ámbitos y contextos discursivos. De este modo, en el marco de la ejecución de un programa o una política, existe un ejercicio de mediación efectuada por técnicos, funcionarios y destinatarios que necesariamente ofrece matices a las definiciones y categorizaciones operativas formales y académicas.

Teniendo en cuenta estos aspectos, pensamos que la actual generalización del término agricultura familiar, se ha presentado como un esfuerzo cognitivo y político por parte de científicos sociales, técnicos, funcionarios de la administración pública y organizaciones agrarias (gremiales, profesionales y movimientos sociales) cuyo fin ha sido el de crear un nuevo marco de referencia para los gobiernos y las instituciones del ámbito local e internacional, donde se reconociera su papel estratégico en los procesos de desarrollo social y económico de los territorios rurales y su necesaria participación para la elaboración de políticas públicas (Schneider, 2014).

Para Bourdieu (1997), uno de los mayores poderes del Estado consiste en producir e imponer las categorías de percepción y de pensamiento que luego aplicamos espontáneamente a cualquier cosa del mundo y al Estado mismo ${ }^{29}$. Por ello, cuando hablamos de agricultu-

29 A esta eficiencia simbólica la llama "espíritu de Estado": "en nuestras sociedades, el Estado contribuye en una parte determinante a la producción y a la reproducción de los instrumentos de construcción de la realidad social. En tanto que estructura organizativa e instancia reguladora de las 
ra familiar no estamos haciendo estricta referencia a las condiciones prediales o filiares de quienes las integran, sino más bien al carácter colectivo de las acciones económicas y políticas de los actores que, por su inserción territorial y local, se inscriben en el campo material $y$ simbólico de la agricultura familiar como un espacio de interlocución público-privado para la canalización de sus demandas, la reivindicación de derechos y la promoción de políticas diferenciales ${ }^{30}$.

El proceso histórico de conformación de muchas organizaciones de la agricultura familiar (luego formalizadas en cooperativas, asociaciones gremiales o movimientos sociales) han tenido su origen en las acciones de los programas de desarrollo rural y en los espacios institucionales de interlocución con el Estado como el FoNAF (Urcola, 2018) o el Consejo Nacional de la Agricultura Familiar, Campesina e Indígena de la ex Secretaría de Agricultura Familiar (SAF). Así, el Estado ha oficiado como gran estructurador interno (Abrams et al, 2015) de las prácticas políticas de estas organizaciones, operando como fuente de legitimación y como arena política para dirimir conflictos y canalizar demandas.

En este sentido, hay una relación constitutiva entre agricultura familiar, Estado y políticas públicas, que no implica necesariamente armonía, pero que sí ha operado como marco de referencia para la acción y el debate empírico-conceptual (como disputa simbólica y de sentido), permitiendo conectar sujetos agrarios, rurales o periurbanos (y hasta urbanos en algunos casos) que de otro modo permanecerían aislados y desprovistos de significado. La figura del Estado aparece como una referencia económica, simbólica y política ineludible sobre la que descansan buena parte de sus posibilidades de reproducción frente a otros actores del agro moderno con mayor capacidad de ne-

prácticas, ejerce permanentemente una acción formadora de disposiciones duraderas, a través de todas las coerciones y de las disciplinas corporales y mentales que impone uniformemente al conjunto de los agentes" (Bourdieu, 1997:117). En un sentido similar se han expresado los autores inscriptos en las corrientes antropológicas del Estado, señalando las instituciones del sistema Estado que tienen la capacidad de producir y recrear categorías específicas de sujetos (Shore, 2010).

30 Tal como señalamos en el planteo introductorio, utilizamos la noción bourdiana de campo para referirnos a la agricultura familiar como un espacio de luchas empíricas y simbólicas entre diferentes actores que pujan por imponer como legítimo aquello que los define colectivamente en relación al resto de la sociedad y al interior del Estado en el marco de las políticas públicas de desarrollo rural. 
gociación y representación política y económica (agricultores empresariales, complejos agroindustrias, proveedores de insumos, agentes de comercialización, etc.).

Por ello, la agricultura familiar ha funcionado durante las últimas dos décadas como un espacio conceptual y empírico singular que ha permitido visibilizar y canalizar las demandas de una gran diversidad de actores agro-rurales (pequeños productores, campesinos o productores familiares capitalizados, pescadores artesanales, miembros de pueblos originarios, productores agroecológicos, trabajadores rurales y población rural con actividades no agrarias), a los que podemos sumar también a técnicos extensionistas y científicos sociales, funcionarios de la administración pública y militantes políticos de diverso orden (campesinitas, ambientalistas, cooperativistas y de la economía social, etc.) que, en su conjunto, reúnen la experiencia reciente de las acciones para el desarrollo rural y la implementación de políticas públicas en los territorios rurales de la Argentina.

\section{Potencialidades de la agricultura familiar como espacio de intervención e investigación para el Trabajo Social}

Hecho este recorrido, cabe introducir algunas reflexiones en torno a las potencialidades que presenta la agricultura familiar como espacio de intervención e investigación social para el Trabajo Social.

Los temas vinculados con el desarrollo rural y la agricultura familiar cuentan con un escaso o residual interés en nuestras currículas y debates académico- profesionales (sobre todo en la región pampeana). En parte, esto se debe en Argentina a cierta invisibilización del campesinado como sujeto, por el peso económico y simbólico de los actores pampeanos con otras características y a los que nunca se tendió a analizar como sujetos de asistencia social ${ }^{31}$.

31 A nivel nacional, la región Pampeana ha resultado históricamente la más relevante en términos de densidad demográfica, producción agropecuaria (especialmente agrícola) y concentración productiva. Si bien el resto de las regiones (NEA, NOA, Cuyo y Patagonia) reúnen mayor superficie, su capacidad productiva y demográfica es significativamente menor y con indicadores de desarrollado más bajos. 
A su vez, la concentración poblacional e industrial en esta región hizo que los debates nacionales se preocuparan más por los conflictos y dinámicas urbanas entre capital y trabajo y aquellos relacionados al sector agrario más dinámico vinculado a la exportación de cereales y oleaginosas. A esto podríamos agregar que la población rural Argentina es escasa (9\%, según Censo Nacional, 2010) y en sostenido retroceso (según los datos intercensales 2001-2010) en comparación con las realidades de otros países del continente Latinoamericano.

Por ello, en las unidades académicas radicadas en grandes ciudades de la región pampeana, como la Universidad Nacional de Rosario (UNR) -por ejemplo-, la formación de grado en Trabajo Social ha estado direccionada a pensar la intervención y la investigación en el marco de una cuestión social urbana con escasas referencias a lo rural y la cuestión agraria.

A esto habría que agregar que en Argentina no se ha logrado instalar nunca una seria discusión en torno a los usos y distribución de la tierra. Los debates y programas de Reforma Agraria (truncos) que acontecieron en la mayoría de los países latinoamericanos de la década de 1960, no tuvieron sus equivalentes en nuestro país. Y los programas de desarrollo rural que se instalan incipientemente en la década de 1980 y definitivamente en el contexto de ajuste estructural de la década de 1990, focalizaron sus intervenciones en los pequeños productores rurales de los territorios extra-pampeanos a los que se asociaba con situaciones de pobreza y se debía asistir técnica y financieramente (véase Lattuada et al, 2015).

Por más que dichos programas estaban destinados a la asistencia de los sectores vulnerables, la visión productivista de los mismos y del

En dichas regiones se ha concentrado la mayor cantidad de población rural y de pequeños productores agropecuarios de base campesina y aborigen aglutinados en torno a actividades económicas agrícolas y agroindustriales específicas (cítricos, manzanas, peras, uvas, aceitunas, azúcar, tabaco, yerba, miel, algodón, etc.). Teniendo en cuenta estos aspectos comunes y el peso económico y social de la región pampeana, tanto en medios académicos como en el ámbito de las políticas públicas y de la cooperación internacional para el desarrollo rural, se ha tendido a nombrar conjuntamente a estas regiones como “extra pampeanas” o "economías regionales” (véase Rofman \& Romero, 1974). Estos aspectos se relacionan con la "ausencia" y pérdida de politicidad de la noción de campesinado en el agro argentino que dará rápida entidad a la noción más "lavada" y "técnica" de pequeño productor de base familiar. Recién a mediados de los '80 se resignifica positivamente el campesinado argentino a través de las acciones del MOCASE en Santiago del Estero y de ONGs de desarrollo rural en el norte del país (véase Barbetta et al, 2014). 
INTA como institución emblemática del Estado argentino con presencia territorial reconocida por los pobladores rurales, dio lugar un espacio de intervención mayoritariamente ocupado por un perfil profesional técnico-agronómico. La concepción de la extensión rural que primaba en las lógicas de intervención de aquellos programas, asociaba asistencia con transmisión de conocimientos técnico-productivos.

Sin embargo, en el nuevo contexto inaugurado de 2003 a esta parte en Argentina, las propuestas de Desarrollo de los Territorios Rurales (DTR) que sostenían una mirada integral sobre las intervenciones generó un terreno fértil para la inclusión y aporte disciplinar específico del Trabajo Social. La impronta interventiva que a partir de entonces tuvieron algunos programas como el PSA (Programa Social Agropecuario) y posteriormente la Subsecretaría de Agricultura Familiar (SAF), fomentaron el abordaje integral de las problemáticas agro-rurales y la articulación de las acciones y miradas disciplinares en el territorio (de ingenieros agrónomos, veterinarios, antropólogos, psicólogos y trabajadores sociales) con propuestas productivas y organizacionales para la comercialización, pero también para la defensa de derechos ciudadanos (reclamos por agua, tierras, vivienda, acceso a salud, jubilación, etc. $)^{32}$.

En la lógica de acción de los trabajadores de la SAF, los agricultores familiares se constituyeron en sujetos de derechos en el sentido más amplio del término, no sólo focalizando la atención en el carácter mercantil simple de los procesos económicos que los involucraban, sino dándole relevancia también al mundo cultural y de relaciones que los comprendía (Nogueira et al, 2017). Esta cuestión no ha resultado menor para la inserción profesional de muchas Trabajadoras Sociales en dicho ámbito institucional, puesto que les permitió un encuadre más propicio para sus intervenciones, aunque no libre de

32 La SAF, dependiente del ex MAGyP y con estrecho vínculo con el Ministerio de Desarrollo Social, se crea en 2009 legitimando una secretaría específica al interior del Estado que se dedicaba junto con otros programas (con financiamiento internacional) a atender las necesidades específicas de los pequeños productores, campesinos, comunidades indígenas, pescadores artesanales, trabajadores rurales sin tierra y pobladores rurales de bajos recursos comprendidos dentro del universo de la agricultura familiar. La misma se instala sobre la base del PSA, uno de los programas emblemáticos de asistencia a la pobreza rural de la década de 1990. 
conflictos y discusiones con las disciplinas ya insertas y de larga trayectoria en la extensión rural.

En función de las entrevistas realizadas con algunas de las Trabajadoras Sociales insertas en la SAF (fundamentalmente de la región pampeana) $)^{33}$, pudimos observar cómo las mismas fueron construyendo su lugar y espacio de intervención en base a la intuición personal y la adaptación de herramientas conceptuales y operativas aprendidas en la academia o en otros espacios laborales, pero sin claras referencias a las particularidades de las problemáticas y contradicciones del mundo agrario o rural, salvo a partir de los diálogos con otras disciplinas afines como la sociología y la antropología para las que desde hace mucho existe la especificidad "rural" 34 .

Resulta relevante destacar estos espacios de intervención vinculados directamente a la temática de la agricultura familiar por la impronta innovadora que presentaron en términos interventivos generales y específicamente para la inserción de nuestro perfil profesional en el ámbito rural entre los años 2009 y 2015. Pero también nos sirve para reflexionar sobre su necesaria integración en nuestros debates académicos en Trabajo Social. En primer lugar, porque en la actualidad (2016-2019) se están intentando anular como espacios de intervención a partir del despido de personal y vaciamiento de la SAF (en Santa Fe, por ejemplo, echaron a todas las Trabajadoras Sociales) ${ }^{35}$. Y, en segundo lugar, porque la agricultura familiar resulta una clave analítica relevante para en-

33 Con la publicación del Decreto 174 de marzo de 2018, el Ministerio de Agroindustria concretó una profunda reforma de su estructura, reduciendo numerosas áreas con el objetivo de desburocratizar y reducir la planta política, eliminando más de 80 direcciones y coordinaciones y despidiendo (entre abril y agosto del mismo año) a alrededor de 900 trabajadores en todo el país (en su mayoría personal técnico de la SAF). En la segunda tanda de despidos de agosto de 2018, "la cartera agraria anunció el despido de 548 trabajadores como parte de la reestructuración dispuesta dentro del recorte de hasta un $10 \%$ asumido para su Presupuesto 2018 (...). Según trascendió oficialmente, del total de personas desvinculadas, 34 trabajadores se desempeñaban en la Subsecretaría de Coordinación Administrativa, 67 en la Secretaría de Agricultura, Ganadería y Pesca, y otros 447 de la Secretaría de Agricultura Familiar" (Infobae, 31 de agosto de 2018).

34 Ente ellas, quisiera expresar un especial agradecimiento a las colegas Elina Ventura, Verónica Radosevich y Silvia Magdsick.

35 Muchas de estas colegas se encuentran realizando estudios de posgrado en relación a estas temáticas como forma de especializarse y nutrirse de enfoques teóricos adecuados para enmarcar su intervención. 
marcar las intervenciones de las colegas que trabajan en comunas y pueblos rurales, las que trabajan en zonas periurbanas de las ciudades o para las que se encuentran activas en el marco de las acciones de ONGs o movimientos sociales agroambientales o de la economía social y popular.

Tradicionalmente, tanto desde el sentido común como desde la producción teórica de las ciencias sociales, se hallaba arraigada la idea de que existía una oposición entre campo y ciudad en la cual, la primera era sede del arcaísmo cultural y el atraso material, mientras que la segunda albergaba el progreso y la prosperidad moderna (Crovetto, 2019). De este modo, las concepciones de lo urbano y lo rural se construyeron históricamente como un par de conceptos opuestos, donde lo rural se delimitaba a partir de sus diferencias con lo urbano (lo que no es urbano es rural) en lo que tiene que ver con la disposición espacial (concentracióndispersión) y en lo que tiene que ver con el mundo de relaciones sociales y culturales (modo de vida tradicional-moderno) que implican uno y otro. A su vez, la visión tradicional de ruralidad establecía una coincidencia entre lo rural y lo agrícola y, la misma, era una categoría residual frente a los procesos de industrialización y urbanización de las sociedades modernas. El concepto mismo de desarrollo, asociado al progreso, llevaba una dirección unívoca que iba desde lo rural hacia lo urbano, de la agricultura hacia la industria, del campo a la ciudad y de la situación de atraso hacia la de bienestar.

Estas perspectivas permearon y delimitaron campos de intervención e investigación específicos durante buena parte del siglo XIX y XX. No obstante, tal como sostienen Schtmidt et al (2019), ante la creciente complejización actual de las relaciones sociales entre los actores de las zonas urbanas y rurales, esta dicotomía está perdiendo capacidad explicativa.

El contexto de reprimarización de las economías de nuestro continente a partir del boom de los comodities y el auge de los modelos socio-productivos neo-extractivitas o neo-desarrollistas nos invita a prestar especial atención a las conflictividades en tor- 
no a los usos del territorio y las formas de producir en el mismo (Svampa, 2008), no sólo por la centralidad de estos aspectos en la dinámica general de nuestras sociedades, sino porque la especificidad y división clásica entre lo urbano y lo rural ha empezado a diluirse cada vez más: con población que vive en el campo y trabaja en la ciudad y viceversa o por los problemas globales que trae aparejado este modelo productivo en las ciudades y sus alrededores: boom inmobiliario y presión sobre los alquileres, contaminación y problemas de salud derivados de la aplicación de agrotóxicos, desplazamiento de pobladores rurales hacia los centros urbanos (campesinos e indígenas fundamentalmente), catástrofes naturales (inundaciones) derivadas de las formas de explotación de la naturaleza (extractivismo minero, petrolero o vinculado a cultivos intensivos como la soja), etc.

Estamos frente a una nueva serie de problemáticas propias de estas áreas mixtas o de interfase entre el campo y la ciudad (Schmidt et al, 2019) que nos desafía a repensar el rol del Estado, las políticas públicas y los encuadres interpretativos con los que delimitamos nuestras intervenciones y espacios a acción profesional. El periurbano, por ejemplo, es uno de esos ámbitos (propios de nuestro ejercicio profesional) que no se encuentra claramente definido en el marco de las políticas públicas y opera como zona de frontera entre el campo y la ciudad: es una zona tradicionalmente asignada para la producción y abastecimiento de alimentos fruti-hortícolas y animales de las ciudades, pero también para la localización de asentamientos irregulares y barrios residenciales o de espacios recreativos y clubes deportivos. Según Feito et al (2019) estos espacios han sufrido una presión "desde adentro" de las ciudades por el mercado inmobiliario y una presión "desde afuera" por la competencia sobre el uso del suelo para el cultivo desoja. Estas presiones se enmarcan, a su vez, en el actual debate académico y gubernamental sobre los dos modelos posibles para el desarrollo del agro argentino: la agricultura familiar y agroecología (que promueve la ocupación progresiva del espacio periurbano con producciones de alimentos sanos y de proximidad) versus el 
agronegocio (que alienta el avance indiscriminado de la soja que produce entre otros efectos negativos, el corrimiento de las producciones tradicionales intensivas).

Resulta relevante como algunas organizaciones sociales inscriptas en el campo de la agricultura familiar, como la Unión de Trabajadores de la Tierra (UTT), están poniendo en discusión esta espacialidad de frontera a través de acciones e intervenciones en espacios públicos urbanos, cuya finalidad es visibilizar las problemáticas de las familias productoras de alimentos que habitan y trabajan en los periurbanos ${ }^{36}$. En este contexto, uno de sus dirigentes señala pertinentemente que la dicotomía entre lo urbano y lo rural se desdibuja "cuando empezamos a pensar no en el territorio sino en el sujeto" (Nahuel Levaggi -UTT- en Schmidt et al, 2019:10).

En este sentido, la agricultura familiar se presenta como una categoría que permite pensar la territorialidad rural y urbana desde el sujeto y sus estrategias productivas, estilos de vida y demandas sociales específicas, que cuenta con una larga tradición y que es objeto de disputas empírico-conceptuales en el marco de las políticas públicas. A su vez, nos permite invertir la tradición académica que piensa al campo desde la ciudad, para reflexionar sobre algunas de las problemáticas urbanas en clave agraria, rural, ambiental o como queramos llamar a la conflictividad que emerge en torno a las formas de apropiación y uso de los territorios y sus recursos o bienes naturales. Finalmente, dicha categoría también nos habilitaría a recuperar algunos de los debates teórico-metodológicos que formaron parte de nuestra tradición académica y que podríamos retomar como piso para reflexionar sobre nuestras intervenciones y rol profesional en el marco de la conflictividad eco-territorial actual. Entre ellos (y sólo a modo de ejemplo) po-

36 Desde el año 2016 está organización viene realizando "feriazos" y "verdurazos" en diferentes espacios públicas de las grandes ciudades, como estrategia para la visbilización de sus demandas y problemáticas específicas. En las mismas, los quinteros que habitan los periurbanos ofrecen sus productos a muy bajo costo para establecer un diálogo sin intermediarios entre productor y consumidor (véase: La realidad detrás de los verdurazos, en Pagina 12, 21/01/19. Recuperado de https://www. pagina12.com.ar/169801-la-realidad-detras-de-los-verdurazos. Última consulta 29/07/19). 
demos identificar el Desarrollo de la Comunidad y la propuesta pedagógica de educación popular de Paulo Freire.

En ambas propuestas, que han tenido y tienen gran influencia en nuestra formación, una de sus mayores referencias empíricas (aunque no exclusivas) han sido las comunidades rurales y el campesinado como sujeto de transformación social. Una desde la perspectiva de la modernización, en el acompañamiento de las comunidades de base campesina hacia el desarrollo de sus potencialidades económicas e integración social (pensando el desarrollo desde lo rural hacia lo urbano y de lo agrario a lo industrial, asociando lo rural-campesino con el atraso y el subdesarrollo) ${ }^{37}$. La otra, desde la perspectiva de la educación popular, viendo en el campesinado a un sujeto de cambio y entendiendo al proceso pedagógico de enseñanza de la lectoescritura como una acción de redescubrimiento del mundo y sus contradicciones, que puede y debe ser transformado ${ }^{38}$.

La agricultura familiar se presenta como un paraguas conceptual y empírico fértil donde anclar nuestras prácticas como Trabajadores Sociales en la medida que el mismo nos permitiría recupera parte de nuestra tradición vinculada a la asistencia sobre los sectores subalternos del agro y nos brindaría la oportunidad

\footnotetext{
37 Si bien el concepto de comunidad y la organización comunitaria reconocen antecedentes de larga data en las producciones de las propias pioneras del Trabajo Social (Eito y Gómez, 2013), a los fines de la temática propuesta nos parece relevante recuperar las perspectivas del desarrollo de la comunidad promovidas por organismos internacionales en la década de 1950 y que enmarcará los debates conceptuales y metodológicos del Trabajo Social Comunitario latinoamericano de aquel entonces (Ware, 1988), así como las posteriores críticas al carácter funcionalista y desarrollista de estas propuestas que harán los autores de la reconceptualización en la década de 1960 (Ander-Egg, 1992).

38 Es sabido que buena parte de las experiencias empíricas a partir de las cuales Freire ha elaborado su obra, Pedagogía del Oprimido (Freire, 1970), refieren a experiencias de alfabetización y reforma agraria en el norte de Brasil y Chile (durante su exilio). No obstante, cabe aclarar que la influencia de esta obra en los años '70 es tan marcada, que su impronta puede observarse tanto en experiencias educativas rurales como urbanas (Puiggrós, 1993). En su perspectiva dialógica de la educación, siempre ha integrado dentro de una misma clase subalterna u oprimida a "proletarios urbanos, campesinos y hombres de clase media" (Freire, 1970:23), con ejemplos que refieren a situaciones y contextos diversos en los que se experimenta el acto de enseñanza-aprendizaje y la explotación-opresión de hombres históricos concretos (véase Freire, 1970:21 y 132). Teniendo en cuenta estos aspectos y a los fines del interés particular de este ensayo, tal vez resulte interesante resaltar un texto donde Freire analiza específicamente el problema de la comunicación entre el técnico y el campesino, poniendo en discusión el rol del agrónomo, "llamado erróneamente extensionista", en los procesos de desarrollo y destacando el papel que el mismo puede desempeñar como educador y a la comunicación como principal herramienta pedagógica para la transformación social (Freire, 1973).
} 
actual de inscribirnos en los debates que se preguntan por las alternativas al modelos de desarrollo imperante y a las acciones que intentan promover "otras formas de hacer agricultura y producir alimentos" y otras formas de habitar los territorios rurales y urbanos.

\section{Reflexiones finales}

En este artículo nos hemos propuesto presentar los ejes centrales que hacen a la agricultura familiar como categoría empírica y analítica que expresa las contradicciones y conflictos del mundo agrario y rural actual. Para ello, la hemos desagregado expositivamente en dos dimensiones: una teórico-conceptual, que refiere sus usos académicos para la descripción, clasificación e identificación de sujetos y dinámicas socio-económicas propias del mundo rural, y otra políticoinstrumental, que refiere a su utilización como encuadre conceptual para la articulación, visibilización y canalización de las demandas de una gran diversidad de actores agro-rurales en el marco de políticas públicas de desarrollo rural.

En función de esto, hemos presentado algunas reflexiones sobre su potencialidad actual para la el desempaño académico y profesional del Trabajo Social, señalando algunos espacios de intervención habilitados en los últimos años y destacando su pertinencia para pensar la territorialidad rural y urbana desde los sujetos, problemáticas y conflictos que en la actualidad trascienden la dicotomía espacial y analítica del campo y la ciudad.

La creciente conflictividades en torno a los usos del territorio y las formas de producir en el mismo, junto con el mundo de relaciones emergentes y sus problemáticas derivadas, nos desafía a desarrollar abordajes indagatorios situados que permitan romper las barreas disciplinares que históricamente han segmentado tanto los campos de estudios como las iniciativas de política pública.

La agricultura familiar es una de esas perspectivas analíticas que resultarían auspiciosas para el Trabajo Social y que permitiría nexos teóricos y empíricos con otras temáticas derivadas o conexas como el 
de las organizaciones económicas y reivindicativas del campo social y popular, que incluyen: movimientos socio-ambientales o ecologistas, movimientos indígenas y organizaciones campesinas. También habilitaría un diálogo fructífero dentro de la actual perspectiva teórica decolonial: como crítica a la modernidad eurocentrada y a los procesos de colonización que nos han constituido como naciones, ya que en estas propuestas se articula la recuperación de los saberes y tradiciones de los habitantes de nuestro continente (que incluye una amplia gama de actores indígenas, campesinos y campesinas), la revisión sobre las formas de apropiación y distribución de los bienes naturales (con recuperación de saberes ancestrales y las propuestas de la agroecología), las disputa por las formas de organización y gobierno de los territorios (con los ya mencionados movimientos sociales indígenas o socio-ambientales) y, por supuesto, la deconstrucción de las relaciones de género a partir de los feminismos en movimiento (o eco-feminismos).

¿Cuál es el rol y el aporte que el Trabajo Social puede realizar en los contextos de la conflictividad eco-territorial actual? ¿Cómo se desarrolla la dimensión asistencial en la especificidad de la territorialidad y conflictividad rural actual? Estos y otros emergen como interrogantes que debemos empezar a profundizar en el marco de las reflexiones de nuestras prácticas académicas y profesionales.

\section{Referencias bibliográficas}

Abrams, P.; Gupta, A. \& Mitchell, T. (2015). Antropología del Estado. México: Fondo de Cultura Económica.

Ander-Egg, E. (1992). Introducción al Trabajo Social. Madrid, España: Siglo XXI.

Balsa, J. (2012). Agricultura familiar: caracterización, defensa y viabilidad. Revista Interdisciplinaria de Estudios Agrarios, 36, 5-28.

Barbetta, P.; Dominguez, D. \&Sabatino, P. (2014). La persistencia de unaincomodidad: repensando el campesino en la Argentina. Século XXI, Revista de CienciasSociais, 4 (1), 91-113.

Bartolomé, L. (comp.) (1972). Estudio del campesinado. Buenos Aires, Argentina: Periferia. 
Bengoa, J. (2003). 25 años de estudios rurales. Sociologías, 10, 36-98.

Bourdieu, P. (1990). Algunas propiedades de los campos. En P. Bourdieu. (Ed.), Cultura y Sociedad (pp. 91-125). México: Grijalbo.

Bourdieu, P. (1997). Espíritu de Estado. Génesis y estructura del campo burocrático. En P. Bourdieu. (Ed.), Razones prácticas. Sobre la teoría de la acción (pp. 91-125). Barcelona, España: Anagrama.

Craviotti, C. (2014). La agricultura familiar en Argentina: nuevos desarrollos institucionales, viejas tendencias estructurales. En C. Craviotti (Ed.), Agricultura familiar en Latinoamérica: continuidades, transformaciones y controversias (pp. 175-204). Buenos Aires, Argentina: Ciccus.

Crovetto, M. (2019). Espacios rurales y espacios urbanos en la teoría social clásica. Quid $16,11,15-31$.

Eito, A. \& Gómez, J. (2013). El concepto de comunidad y trabajo social. Revista Espacios Transnacionales, 1. Recuperado de: http://www.espaciostransnacionales.org/ conceptos/conceptotrabajosocial/

Feito, C., Boza, S. \& Pereda, S. (2019). La agricultura en los periurbanos de Buenos Aires (Argentina) y Santiago (Chile): territorios en transición. Quid 16, 11, 32-54.

Freire, P. (1970). Pedagogía del oprimido. México: Siglo XXI.

Freire, P. (1973). ¿Extensión o comunicación? La concientización en el medio rural. Buenos Aires, Argentina: Siglo XXI.

Giarracca, N. (Coord.) (1999). Estudios rurales. Teorías, problemas y estratégicas metodológicas. Buenos Aires, Argentina: La Colmena.

Hora, R. (2010). La crisis del campo en otoño del 2008. Desarrollo Económico, 97, 81-111.

Lattuada, M.; Márquez, S. \& Neme, J. (2012). Desarrollo rural y política. Reflexiones sobre la experiencia argentina desde una perspectiva de gestión. Buenos Aires, Argentina: Ciccus.

Lattuada, M. (2014). Políticas de desarrollo rural en la Argentina. Conceptos, contexto y transformaciones. Temas y Debates, 27 (18), 13-47.

Lattuada, M.; Nogueira, M. E. \&Urcola, M. (2015). Tres décadas de desarrollo rural en la Argentina. Continuidades y rupturas de intervenciones públicas en contextos cambiantes (1984-2014). Buenos Aires, Argentina: Teseo.

Manzanal, M. \& Schneider, S. (2011). Agricultura familiar y políticas de desarrollo rural en Argentina y Brasil (análisis comparativo, 1990-2010). Revista Interdisciplinaria de Estudios Agrarios, 34, 35-71. 
Nogueira, M. E. \&Urcola, M. (2013). La jerarquización de la agricultura familiar en las políticas de desarrollo rural en Argentina y Brasil (1990-2011). Revista IDeAS. Interfaces em Desenvolvimento, Agricultura e Sociedade, 7 (2), 96-137.

Nogueira, M. E.; Urcola, M. \&Lattuada, M. (2017). La gestión estatal del desarrollo rural y la agricultura familiar en Argentina: estilos de gestión y análisis de coyuntura (2004-2014 y 2015-2017). Revista Latinoamericana de Estudios Rurales (ReLaER), 2 (4), 23-59.

Obschatko, E.; Foti, M. del P. \& Román, M. (2007). Los pequeños productores en la República Argentina. Importancia en la producción agropecuaria y en el empleo en base al Censo Nacional Agropecuario 2002. Buenos Aires, Argentina: SAGPyA- IICA.

Obschatko, E. (2009). Las explotaciones agropecuarias familiares en la República Argentina. Un análisis a partir de los datos del Censo Nacional Agropecuario 2002. Buenos Aires, Argentina: MAGyP-IICA.

Puiggróss, A. (1993). Historia y prospectiva de la educación popular latinoamericana. En M. Gadotti\&C. Torres (Ed.), Educación popular. Crisis y perspectivas (pp. 33-42). Buenos Aires, Argentina: Miño y Dávila.

Rofman, A. \& Romero, L. A. (1974). Sistema socioeconómico y estructura regional en la Argentina. Buenos Aires, Argentina: Amorrortu.

Savourin, E., Samper, M. \& Sotomayor, O. (Ed.) (2014). Políticas públicas y agriculturas familiares en América Latina y el Caribe. Balances, desafíos y perspectivas. Santiago, Chile: CEPAL-IICA.

Schiavoni, G. (2010). Describir y prescribir: la tipificación de la agricultura familiar en la Argentina. En M. Manzanal \& G. Neiman (Ed.), La agricultura familiar del MERCOSUR. Trayectorias, amenazas y desafios (pp. 43-59). Buenos Aires, Argentina: Ciccus.

Schejtman, A. \& Berdegué, J. (2004). Desarrollo Territorial Rural. Temas y Debates Rurales, 1, 1-54.

Schmidt, M.; Wertheimer, M.; Astelarra, S. \& Ejarque, M. (2019). Desbordes de la dicotomía urbano-rural. Quid 16, 11, Presentación del Dossiere, 1-14.

Schneider, S. (2014). La agricultura familiar en América Latina. Un nuevo análisis comparativo. Roma, Italia: Fondo Internacional de Desarrollo Agrícola (FIDA).

Shore, C. (2010). La antropología y el estudio de la política pública: reflexiones sobre la formulación de las políticas. Antípoda, 10, 21-49.

Soverna, S.; Tsakoumagkos, P. \& Paz, R (2008). Revisando la definición de agricultura familiar. Documento de Capacitación $N^{\circ}$ 7. Buenos Aires, Argentina: PROINDER-SAGPyA. 
Svampa, M. (2008). La disputa por el desarrollo: territorios y lenguajes de valoración. En M. Svampa (Ed.), Cambio de época: movimientos sociales y poder politico, (99-114). Buenos Aires, Argentina: Siglo XXI.

Urcola, M. (2011). Reflexiones sobre el modelo familiar de agricultura pampeana. Revista Interuniversitaria de Estudios Territoriales, 7 (7), 87-111.

Urcola, M. (2018). El campo asociativo de la agricultura familiar en la provincia de Santa Fe: del desarrollo rural a la movilización política (2000-2017). Población \& Sociedad, 25 (2), 189-215.

Ware, C. (1988). El desarrollo de la comunidad y el trabajo social en América Latina: mis experiencias (1945-1976). Caracas, Venezuela: Ekíwá.

Recepción: 03/12/2018

Aceptación: 10/08/2019 